Article

\title{
Empirical Models to Characterize the Structural and Physiochemical Properties of Vacuum Gas Oils with Different Saturate Contents
}

\author{
Dicho S. Stratiev ${ }^{1}$, ${ }^{\mathbb{D}}$, Ivelina K. Shishkova ${ }^{1}$, Rosen K. Dinkov ${ }^{1}$, Ivan P. Petrov ${ }^{1}$, Iliyan V. Kolev ${ }^{1}$, \\ Dobromir Yordanov $^{2}$, Sotir Sotirov ${ }^{2}$, Evdokia Sotirova ${ }^{2}$, Vassia Atanassova ${ }^{3}$ D , Simeon Ribagin ${ }^{3}$, \\ Krassimir Atanassov 2,3, Danail D. Stratiev ${ }^{3}$, Svetoslav Nenov ${ }^{4}$, Liliana Todorova-Yankova ${ }^{2}$ \\ and Kamen Zlatanov 4
}

check for updates

Citation: Stratiev, D.S.; Shishkova, I.K.; Dinkov, R.K.; Petrov, I.P.; Kolev, I.V.; Yordanov, D.; Sotirov, S.; Sotirova, E.; Atanassova, V.; Ribagin, S.; et al. Empirical Models to Characterize the Structural and Physiochemical Properties of Vacuum Gas Oils with Different Saturate Contents. Resources 2021, 10, 71. https://doi.org/10.3390/ resources 10070071

Academic Editor: Elena Magaril

Received: 11 June 2021

Accepted: 7 July 2021

Published: 9 July 2021

Publisher's Note: MDPI stays neutral with regard to jurisdictional claims in published maps and institutional affiliations.

Copyright: (c) 2021 by the authors. Licensee MDPI, Basel, Switzerland. This article is an open access article distributed under the terms and conditions of the Creative Commons Attribution (CC BY) license (https:/ / creativecommons.org/licenses/by/ $4.0 /)$.
1 LUKOIL Neftohim Burgas, 8104 Burgas, Bulgaria; Shishkova.Ivelina.K@neftochim.bg (I.K.S.); Dinkov.Rosen.K@neftochim.bg (R.K.D.); Petrov.Ivan.P@neftochim.bg (I.P.P.); Kolev.Iliyan.V@neftochim.bg (I.V.K.)

2 Laboratory of Intelligent Systems, Department of Industrial Technologies and Management, University Prof. Dr. Assen Zlatarov, Professor Yakimov 1, 8010 Burgas, Bulgaria; dobromirj@abv.bg (D.Y.); ssotirov@btu.bg (S.S.); esotirova@btu.bg (E.S.); k.t.atanassov@gmail.com (K.A.); litoian@abv.bg (L.T.-Y.)

3 Institute of Biophysics and Biomedical Engineering, Bulgarian Academy of Sciences, Academic Georgi Bonchev 105, 1113 Sofia, Bulgaria; vassia.atanassova@gmail.com (V.A.); sim_ribagin@mail.bg (S.R.); danail.stratiev@gmail.com (D.D.S.)

4 Department of Mathematics, University of Chemical Technology and Metallurgy, Kliment Ohridski 8, 1756 Sofia, Bulgaria; s.nenov@gmail.com (S.N.); kamenzlatanov99@gmail.com (K.Z.)

* Correspondence: stratiev.dicho@neftochim.bg

Abstract: Inter-criteria analysis was employed in VGO samples having a saturate content between 0.8 and $93.1 \mathrm{wt}$.\% to define the statistically significant relations between physicochemical properties, empirical structural models and vacuum gas oil compositional information. The use of a logistic function and employment of a non-linear least squares method along with the aromatic ring index allowed for our newly developed correlation to accurately predict the saturate content of VGOs. The empirical models developed in this study can be used not only for obtaining the valuable structural information necessary to predict the behavior of VGOs in the conversion processes but can also be utilized to detect incorrectly performed SARA analyses. This work confirms the possibility of predicting the contents of VGO compounds from physicochemical properties and empirical models.

Keywords: vacuum gas oil; empirical models; SARA; ICrA; ARI

\section{Introduction}

Petroleum is a mineral resource used to produce fuels for automotive and aviation transportation, light olefins (in the $\mathrm{C}_{2}-\mathrm{C}_{4}$ range) and aromatics (mostly benzene, toluene and xylenes, BTXs) — the most valuable building blocks of the chemical industry [1]. The demand for oil-derived fuels is expected to decrease after 2030 due to the advances in clean energy generation and strong environmental concerns along with stricter policy [1]. In the next two decades, however, oil demand for petrochemicals is expected to increase by ca. $4 \mathrm{Mb} / \mathrm{d}$ per year, achieving $34 \%$ of the total oil market in 2040, in contrast to the current 15\% [1]. The role of the conversion processes which break the higher molecular weight petroleum hydrocarbons to lower molecular weight ones is expected to grow in the future due to the increased demand of the building blocks for the chemical industry. Fluid catalytic cracking (FCC) and steam cracking (thermal cracking) are the current technologies that provide feedstock for the chemical industry. The performance of these processes has been shown in many studies to strongly depend on the quality of the feedstock [2-17]. The vacuum gas oil fraction from petroleum is the typical feed for the FCC [2,3,5-17] and it has been explored as a feedstock for steam cracking as well [4]. Considering that in 
both FCC and thermal cracking the reactivity of the vacuum gas oils increases with the saturate content enhancement and aromatic carbon content reduction, the information about these vacuum gas oil characteristics is of paramount importance for optimizing their performance [17]. Different empirical models for predicting important vacuum gas oil characteristics have been developed and published in the open literature [18-28]. To the best of our knowledge, these empirical models have not been evaluated to predict the content of saturates of vacuum gas oils in the whole range of possible variation (between 0 and $100 \%$ ). There is also a lack of knowledge about the existence of relations between the VGO characteristics predicted by the empirical models and the content of heavy aromatics (triand tetra+ condensed aromatic rings). The yield of the least valuable product from the VGO conversion processes - the unconverted VGO (bottoms) product-is defined by the content of heavy aromatics because it is difficult to crack $[7,29]$. Considering that the conversion level and the yields of valuable products from the VGO conversion processes depend on the contents of the saturates, aromatic carbon and heavy aromatics we investigated the properties of 74 VGOs published in the open literature [2-4,15,30-40]. The studied VGOs had been characterized by HPLC-MS (high-performance liquid chromatography-mass spectrometry), NMR (nuclear magnetic resonance), SARA (saturates, aromatics, resins, asphaltenes) analysis and the typical physicochemical properties like density, distillation, refractive index, etc. We employed the different empirical models published in the literature and examined their capability to predict the contents of the saturates, aromatic carbon and heavy aromatics in the VGO based on the physicochemical properties which are routinely measured in any petroleum refinery. We made improvements in the correlations where it was necessary and developed a new correlation to predict the saturate content from the VGO physicochemical properties. The aim of this work is to discuss the results of our study.

\section{Materials and Methods}

A total of 74 vacuum gas oils characterized by HPLC-MS, NMR, SARA analysis and density, refractive index, aromatic carbon content, hydrogen content, molecular weight as reported in [2-4,15,33-40] were used in this study (Table S1 from Supplementary material). The empirical models evaluated in this research are summarized below:

\subsection{Determination of Content of Paraffinic Carbon, Naphthenic Carbon and Aromatic Carbon by} the $n-d-M(A S T M D-3238)$

The n-d-M method was originally developed by Van Nes and van Westen [41] and relates the structural group composition determined by the use of NMR in terms of the contents of paraffinic, naphthenic and aromatic carbon to three oil physical properties: refractive index, density and molecular weight. That is why it is called n-d-M method. The $n-d-M$ method does not directly give the composition of vacuum gas oils in terms of paraffins, naphthenes and aromatics. It predicts the distribution of carbon in the paraffins $\left(C_{P}\right)$, naphthenes $\left(C_{N}\right)$ and aromatics $\left(C_{A}\right)$ of studied VGOs. The following equations are used for the estimation of $C_{P}, C_{N}$ and $C_{A}$ :

$$
\begin{gathered}
C_{A}=a v+3660 / M W \\
C_{N}=C_{R}-C_{A} \\
C_{N}=C_{R}-C_{A}
\end{gathered}
$$

Equations (1)-(3) include parameters $a, v, w$ and $C_{R}$, which are estimated by Equations (4)-(7). Equations (4)-(7) are summarized below:

$$
\begin{gathered}
v=2.51(R I-1.475)-(d-0.851) \\
a=430 \text { if } v>0 \\
a=670 \text { if } v<0 \\
w=(d-0.851)-1.11(R I-1.475)
\end{gathered}
$$




$$
\begin{gathered}
\text { if } w>0 \\
C_{R}=820 w-3 S+10000 / M W \\
\text { if } w<0 \\
C_{R}=1440 w-3 s+\frac{10600}{M W}
\end{gathered}
$$

The property range of the n-d-M method as specified in ASTM D-3228 is given below:

- $\quad \% C_{A}: 2.7$ to 34.6

- $\% C_{N}: 23.7$ to 47.2

- $\quad \% C_{P}: 32.3$ to 68.6

- $R_{A}: 0.12$ to 1.69

- $R_{N}: 1.61$ to 2.90

- $R_{T}: 1.73$ to 3.77

2.2. Determination of Content of Paraffinic (P), Naphthenic (N) and Aromatic (A) Portions by API Procedure 2B4.1 and 3

API adopted the methods developed by Riazi and Daubert for the prediction of the content of paraffinic, naphthenic and aromatic portions on the basis of data from distillation characteristics, specific gravity, molecular weight $(M W)$ and carbon to hydrogen ratio. Riazi found that the n-d-M method gives high errors in the prediction of the composition of petroleum fractions [42]. For that reason, Riazi and Daubert developed a set of correlations for molecular type analysis [19]. The API Procedure for predicting the composition of heavy petroleum fractions with $M W>200$ presented in Equations (8)-(10) was used in this study:

$$
\begin{gathered}
P=193.82+0.74855 m-19.966 C H \\
N=-42.260-0.777 m+10.7625 C H \\
A=100-P-N
\end{gathered}
$$

Parameters $m$ and $\mathrm{CH}$ of the investigated VGOs were calculated using the following forms:

$$
\begin{gathered}
m=M W(R I-1.4750) \\
C H=\frac{C}{H}
\end{gathered}
$$

Refractive index of studied VGOs was predicted by using the following equations:

$$
\begin{gathered}
R I=\left(\frac{1+2 I}{1-I}\right)^{\frac{1}{2}} \\
I=1.8422 \times 10^{-2} \exp \left(11.6352 \times 10^{-4} T_{b}+5.144 S G-5.92 \times 10^{-4} T_{b} S G\right) T_{b}{ }^{-0.4077} S G^{-3.333}
\end{gathered}
$$

The property range of the methods developed by Riazi and Daubertas specified in [19] is given below:

- $\quad \% P: 10.2$ to 81.0

- $\% N: 13.3$ to 63.9

- $\% A: 0$ to 44.3

The property range of Riazi and Daubert correlations is wider than that of the n-d$M$ method.

\subsection{Determination of Refractive Index, Aromatic Carbon and Hydrogen Content by the Total Method}

The Total method was originally developed by Dhulesia to predict the aromatic carbon content, hydrogen content and refractive index of fluid catalytic cracking feedstocks [25]. Since the n-d-M method and API procedure were developed mainly on data from lower boiling fractions, the Total method was developed on data from some heavy feeds [21]. This method uses the values of specific gravity, molecular weight, sulfur content, viscosity 
at $98.9^{\circ} \mathrm{C}$ and distillation according to ASTM D1160. Equations (15)-(18) describe the Total method that was used for estimation of the characteristic parameters of the VGOs under study.

$$
\begin{gathered}
C_{A}=-814.136+635.192 R I-129.266 S G+0.013 M W-0.340 S-6.872 \ln (V I S) \\
H=52.825-14.260 R I-21.329 S G-0.0024 M W-0.052 S+0.757 \ln (V I S) \\
R I=1+0.8447 S G^{1.2056}(T+273.16)^{-0.0557} M W^{-0.0044} \\
T=\left(T_{10}+T_{30}+T_{50}+T_{70}+T_{90}\right) / 5
\end{gathered}
$$

Viscosity at $98.9^{\circ} \mathrm{C}$ of studied VGOs was calculated by using the Abbott et al. correlation [30] employing the following equations:

$$
\begin{array}{r}
\log V I S=-0.463634-0.166532(A P I)+5.13447 \times 10^{-4}(A P I)^{2}-8.48995 \times 10^{-3} K_{W}(A P I) \\
F=\frac{8.0325 \times 10^{-2} K_{W}+1.24899(A P I)+0.19768(A P I)^{2}}{(A P I)+26.786-2.6296 K_{W}}
\end{array}
$$

The range of properties of the Total method as specified in [25] is given below:

- $\quad \% C_{A}: 1.2$ to 51.6

- $\% H: 9.6$ to 14.58

- $\quad$ SG: 0.8335 to 1.0133

- $\quad$ RI: 1.4459 to 1.5681

- $\quad T_{10 \%},{ }^{\circ} \mathrm{C}: 27$ to 478

- $\quad T_{50 \%},{ }^{\circ} \mathrm{C}: 385$ to 504

- Viscosity at $98.9^{\circ} \mathrm{C}, \mathrm{mm}^{2} / \mathrm{s}: 3.6$ to 41.8

2.4. Determination of Hydrogen Content and Molecular Weight by the Method of Goosens

Goosens highlighted the importance of accurate hydrogen content prediction of petroleum fractions, which is used as input in the kinetic models that simulate and optimize the performance of conversion processes like steam cracking and catalytic cracking [22]. He reported that while Dhulesia's method exhibited a $1 \%$ average deviation in hydrogen prediction of FCC feeds, Goosens' method achieved a standard deviation of only $0.3 \%$ in predicted wt.\% hydrogen for the full practical range of oil fractions for olefin manufacture. [22]. Goosens' method requires data on the refractive index, density and distillation characteristics of VGOs to predict hydrogen content [22]. It is inferred from the concept of the molar additivity of the structural contributions of the carbon types in the average hydrocarbon molecule. The following equations were used to calculate the molecular weight and hydrogen content of the studied VGOs:

$$
\begin{aligned}
& M W=0.010770 T_{b}^{\left[1.52869+0.06486 \ln \left(\frac{T_{b}}{1078-T_{b}}\right)\right]} / d \\
& H=30.346-\frac{65.341 R I}{d}+\frac{82.952}{d}-306 M W
\end{aligned}
$$

The property range of Goosens' method as specified in [22,23] is given below:

- $\quad M W, \mathrm{~g} / \mathrm{mol}: 84$ to 459 [22]; 76 to 1685 [23]

- $\% H: 12.18$ to 15.64

- $d, \mathrm{~g} / \mathrm{cm}^{3}: 0.6775$ to 0.9292 [22]; 0.63 to 1.08 [23]

- $\quad$ RI: 1.3832 to 1.5141

2.5. Determination of Aromatic Carbon and Hydrogen Content by the Conoco Philips Method (COP)

The COP method can accurately predict the carbon aromatic and hydrogen contents of heavy petroleum fractions, employed as feeds for fluid catalytic cracking and hydroprocessing, on the basis of routine analysis data-the specific gravity and $T_{50 \%}\left({ }^{\circ} \mathrm{F}\right)$. It was developed to accurately estimate aromatic carbon and hydrogen content for the entire heavy petroleum range [21]. In contrast to the Total method that was based on 33 petroleum samples, the COP method was developed based on 354 heavy petroleum samples [21]. 
Equations (23) and (24) were used to estimate the aromatic carbon and hydrogen content of investigated VGOs.

$$
\begin{gathered}
C_{A}=292.1 S G-0.043 T_{50}^{F}+35.2 \\
H=-26.25 S G+0.0013 T_{50}^{F}+35.2
\end{gathered}
$$

The property range of the COP method as specified in [21] is given below:

- $\% C A: 14.0$ to 75.0

- $\% H: 8.2$ to 13.1

- $\quad A P I(S G):-2.7$ to 28 (0.887 to 1.098$)$

- $\quad$ RI: 1.485 to 1.660

- $T_{10 \%},{ }^{\circ} \mathrm{C}: 277$ to 418

- $T_{50 \%},{ }^{\circ} \mathrm{C}: 354$ to 546

This investigation has also evaluated the refractive index correlations reported by Stratiev et al. in [31,32], Equations (25) and (26).

$$
\begin{gathered}
R I_{L N B}=0.702091 d_{15}-0.00011 T_{50}+0.91493 \\
R I=0.77887 d_{15}+0.80065
\end{gathered}
$$

The property range of the Stratiev et al. method as specified in [30,31] is given below:

- $\quad$ RI: 1.4747 to 1.6538

- $T_{50 \%},{ }^{\circ} \mathrm{C}: 243$ to 475

- $d_{15}, \mathrm{~g} / \mathrm{cm}^{3}: 0.8630$ to 1.0971

2.6. Aromatic Ring Index (ARI), Developed by Abutaqiya et al. Is a Characterization Factor, Which Is a Function of Molecular Weight and Refractive Index and Is Used to Estimate the Average Aromatic Ring Numbers in the Average Hydrocarbon Structure of the Investigated Vacuum Gas Oils. ARI Is Estimated by Equations (27) and (28)

$$
A R I=f\left(M W, F_{R I}\right)=\frac{2\left[\frac{M W}{F_{R I}}-(3.5149 M W+73.1858\}\right.}{(3.5074 M W-91.972-(3.5149 M W+73.1858)}
$$

where,

$M W=$ molecular weight of EBVRHC heavy oils, $\mathrm{g} / \mathrm{mol}$;

$F R I=$ function of refractive index

$$
F_{R I}=\frac{n_{D 20}^{2}-1}{n_{D 20}^{2}+2}
$$

where, $n_{D 20}=$ refractive index at $20^{\circ} \mathrm{C}[26,27]$.

The methods discussed in this section describe the complex mixture, which is the VGO, in terms of average structural features of the molecules, that is, groups of carbon and/or hydrogen types, in contrast to the compound group. These methods do not provide information in terms of compound types such as saturates, aromatics, mono, di, tri and four plus aromatics. Compound group type methods are based on mass spectrometry (MS) [43]. It was shown in our earlier research [31] that the content of saturates and mononuclear aromatics measured by MS can be reasonably well predicted by the empirically estimated aromatic carbon and hydrogen content. However, the property range of variation of the VGOs employed in [31] was narrower than that used in this study. The variation of hydrogen content in our recent investigation [31] was between 7.6 and $13.6 \mathrm{wt} . \%$ and that of aromatic carbon content was between 4.3 and $73.5 \mathrm{wt} . \%$.

\section{Results}

3.1. Evaluation of VGO Property Relations and Predictions of the Empirical Models and Development of New Empirical Models

Table 1 summarizes the range of variation of the evaluated vacuum gas oils. It is evident from these data that the range of variation in the composition and in the physical and chemical properties is very big and is wider than the property ranges for the empirical 
models discussed in the Materials and Methods section. Therefore, it could be considered representative enough for the purpose of the investigation of the vacuum gas oil properties' relations. Inter-criteria analysis (ICrA) was employed to search for statistically significant relationships between different VGO properties. The reader can find more information concerning the application of ICrA in our recent studies [7,44]. ICrA defines the relations between the studied criteria (parameters) in terms of intuitionistic fuzzy pairs $\langle\mu, v\rangle[7,44]$. Depending on the values of $\mu, v$ seen in pair, positive consonance, negative consonance and dissonance between any pair of criteria (parameters) can be defined. Values of $\mu=0.75 \div 1.00$ and $v=0.00 \div 0.25$ denote a statistically meaningful positive relation, where the strong positive consonance is exhibited at values of $\mu=0.95 \div 1.00$, $v=0.00 \div 0.05$ and the weak positive consonance is exhibited at values of $\mu=0.75 \div 0.85$, $v=0.15 \div 0.25$. Respectively, the values of negative consonance with $\mu=0.00 \div 0.25$ and $v=0.75 \div 1.05$ represent a statistically meaningful negative relation, where the strong negative consonance exhibits values of $\mu=0.00 \div 0.05, v=0.95 \div 1.00$ and the weak negative consonance exhibits values of $\mu=0.15 \div 0.25, v=0.15 \div 0.25$. All other cases are characterized as dissonance $[7,44]$.

Table 1. Range of variation in the properties of the studied vacuum gas oils.

\begin{tabular}{lcc}
\hline & Min & Max \\
\hline Density at $15^{\circ} \mathrm{C}(\mathrm{g} / \mathrm{mL})$ & 0.801 & 1.065 \\
$\mathrm{Kw}$ & 10.72 & 13.47 \\
$\mathrm{MW}$ & 258 & 715 \\
Kin. viscosity at $100^{\circ} \mathrm{C}$ & 2.6 & 161.66 \\
$T_{50 \%}$ & 369 & 620 \\
$\mathrm{CCR}$, wt. $\%$ & 0 & 11 \\
Hydrogen content $(\mathrm{wt} \%$ \%) & 6.88 & 15.59 \\
$\mathrm{H} / \mathrm{C}$ atomic ratio & 1.03 & 2.23 \\
Total Nitrogen Content $(\mathrm{wppm})$ & 0 & 4122 \\
Basic Nitrogen Content $(\mathrm{wppm})$ & 0.5 & 1543 \\
Sulphur $\%$ & 0.0008 & 4.6 \\
Aromatic Carbon Content, wt. $\%$ & 4.4 & 82 \\
Aniline Point, ${ }^{\circ} \mathrm{C}$ & 33.1 & 99.8 \\
Refractive Index at $20^{\circ} \mathrm{C}$ & 1.4747 & 1.5695 \\
Saturates & 0.8 & 90.1 \\
Paraffins & 0 & 35.2 \\
Cyclo-paraffins & 16.7 & 68.4 \\
Aromatics & 9.3 & 99.2 \\
mono-ARO & 6.87 & 31.3 \\
di-ARO & 0.7 & 42.56 \\
tri-ARO & 0.1 & 45.33 \\
tetra- and greater ARO & 0.5 & 74.94 \\
Aromatic Sulfur & 0.1 & 10.7 \\
Polar Compounds & 0.7 & 15.2 \\
\hline
\end{tabular}

Table 2 presents the statistically significant relations quantified by $\mu$-value of ICrA for the evaluated vacuum gas oils. The data in Table 2 indicate that density strongly negatively correlates with hydrogen content $(\mu=0.02), \mathrm{H} / \mathrm{C}$ atomic ratio $(\mu=0.03)$ and strongly positively with refractive index $(\mu=0.98)$. The density intermediately negatively correlates with saturate content $(\mu=0.07)$ and intermediately positively with aromatic carbon content $(\mu=0.91)$ and weakly positively with di-nuclear aromatic hydrocarbons $(\mu=0.76)$. These data confirm that density is a property that well describes aromaticity and hydrogen deficiency as already reported in our recent studies [44,45]. Kw-factor strongly negatively correlates with the aromatic carbon content $(\mu=0.05)$ and strongly positively with $\mathrm{H} / \mathrm{C}$ atomic ratio $(\mu=0.96)$. This finding is in line with the results reported in our recent research [46] showing that the Kw-factor correlates with the aromaticity of petroleum and petroleum products. Hydrogen content strongly negatively correlates with aromatic carbon content $(\mu=0.02)$ and with refractive index $(\mu=0.02)$. The hydrogen strongly positively 
correlates with the aniline point and intermediately positively correlates with the saturate content. The refractive index strongly negatively correlates with the aromatic carbon content. These data show that density, refractive index and hydrogen content strongly correlate with the aromatic carbon content and they also correlate with each other. Figure 1 exemplifies these correlations. They were used to estimate some of the properties employed in Equations (4) and (5). The relationship between density and refractive index shown in Figure $1 \mathrm{~b}$ was juxtaposed against the correlations predicting refractive index reported in $[20,25,31,32]$. Table S4 from Supplementary material presents a comparison between measured and predicted by the empirical correlations refractive index: Equations (13), (19), (31), (32) and Figure 1b. It is evident from these data that the average absolute deviation increases in the order: Equation (30) $(\mathrm{AD}=0.0044)<$ Equation $(19)(\mathrm{AD}=0.0047)<$ Equation (Figure 1b; $\mathrm{AD}=0.0078)<$ Equation (31) $(\mathrm{AD}=0.0094)<$ Equation (13) (0.0104). Based on these data one may conclude that density and $T_{50 \%}$ are the VGO characteristics that best describe the refractive index.

Table 2. $\mu$-value of the ICrA evaluation of relationships between properties of the studied vacuum gas oils from different origins.

\begin{tabular}{|c|c|c|c|c|c|c|c|c|c|c|c|c|}
\hline & D15 & Kw & VIS100 & $\mathrm{H}$ & $\mathrm{H} / \mathrm{C}$ & CA & $\mathbf{A P}$ & RI & Sat. & Aro & Tri-Aro & $4+\mathrm{ARO}$ \\
\hline D15 & 1.00 & & & & & & & & & & & \\
\hline Kw & 0.12 & 1.00 & & & & & & & & & & \\
\hline CCR & 0.52 & 0.49 & 0.97 & & & & & & & & & \\
\hline $\mathrm{H}$ & 0.02 & 0.92 & 0.38 & 1.00 & & & & & & & & \\
\hline $\mathrm{H} / \mathrm{C}$ & 0.03 & 0.96 & 0.33 & 1.00 & 1.00 & & & & & & & \\
\hline $\mathrm{C}_{\mathrm{A}}$ & 0.91 & 0.05 & 0.05 & 0.02 & 0.03 & 1.00 & & & & & & \\
\hline $\mathrm{AP}$ & 0.07 & 0.85 & 0.28 & 0.96 & 0.94 & 0.08 & 1.00 & & & & & \\
\hline RI & 0.98 & 0.10 & 0.27 & 0.01 & 0.01 & 0.04 & 0.06 & 1.00 & & & & \\
\hline Sat. & 0.07 & 0.70 & 0.49 & 0.92 & 0.85 & 0.12 & 0.85 & 0.09 & 1.00 & & & \\
\hline Par. & 0.19 & 0.35 & 0.50 & 0.74 & 0.84 & 0.46 & 0.68 & 0.32 & 0.78 & & & \\
\hline Naph. & 0.30 & 0.64 & 0.36 & 0.61 & 0.56 & 0.26 & 0.71 & 0.34 & 0.76 & & & \\
\hline Aro & 0.46 & 0.20 & 0.32 & 0.38 & 0.40 & 0.51 & 0.07 & 0.63 & 0.24 & 1.00 & & \\
\hline DI-Aro & 0.76 & 0.22 & 0.20 & 0.03 & 0.20 & 0.50 & 0.15 & 0.04 & 0.47 & 0.28 & & \\
\hline Tri-Aro & 0.50 & 0.30 & 0.03 & 0.51 & 0.40 & 0.74 & 0.33 & 0.55 & 0.40 & 0.67 & 1.00 & \\
\hline $4+\mathrm{ARO}$ & 0.40 & 0.38 & 0.22 & 0.20 & 0.32 & 0.89 & 0.29 & 0.78 & 0.28 & 0.78 & 0.84 & 1.00 \\
\hline Polars & 0.60 & 0.36 & 0.72 & 0.40 & 0.42 & 0.46 & 0.49 & 0.56 & 0.34 & 0.53 & 0.19 & 0.31 \\
\hline $\begin{array}{c}\text { Heavy } \\
\text { ARO }\end{array}$ & 0.62 & 0.27 & 0.21 & 0.27 & 0.42 & 0.87 & 0.13 & 0.70 & 0.31 & 0.76 & 0.93 & 0.98 \\
\hline
\end{tabular}

Note: The figures in bold concern statistically meaningful relations.

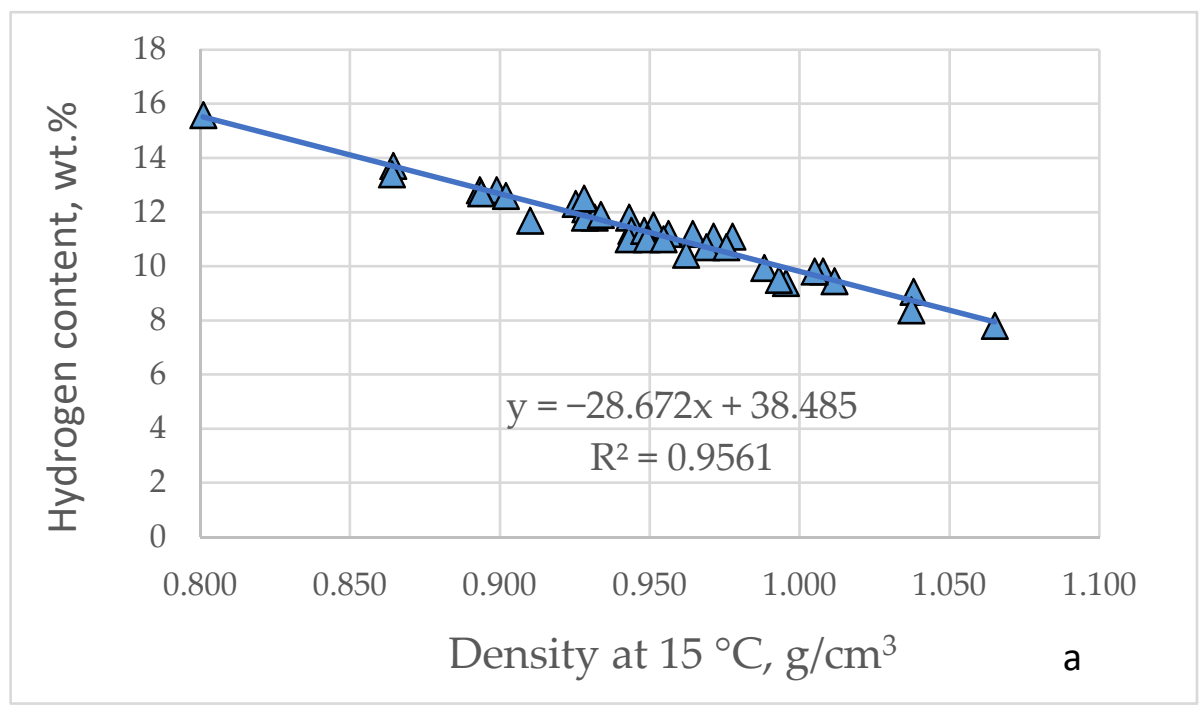

(a)

Figure 1. Cont. 


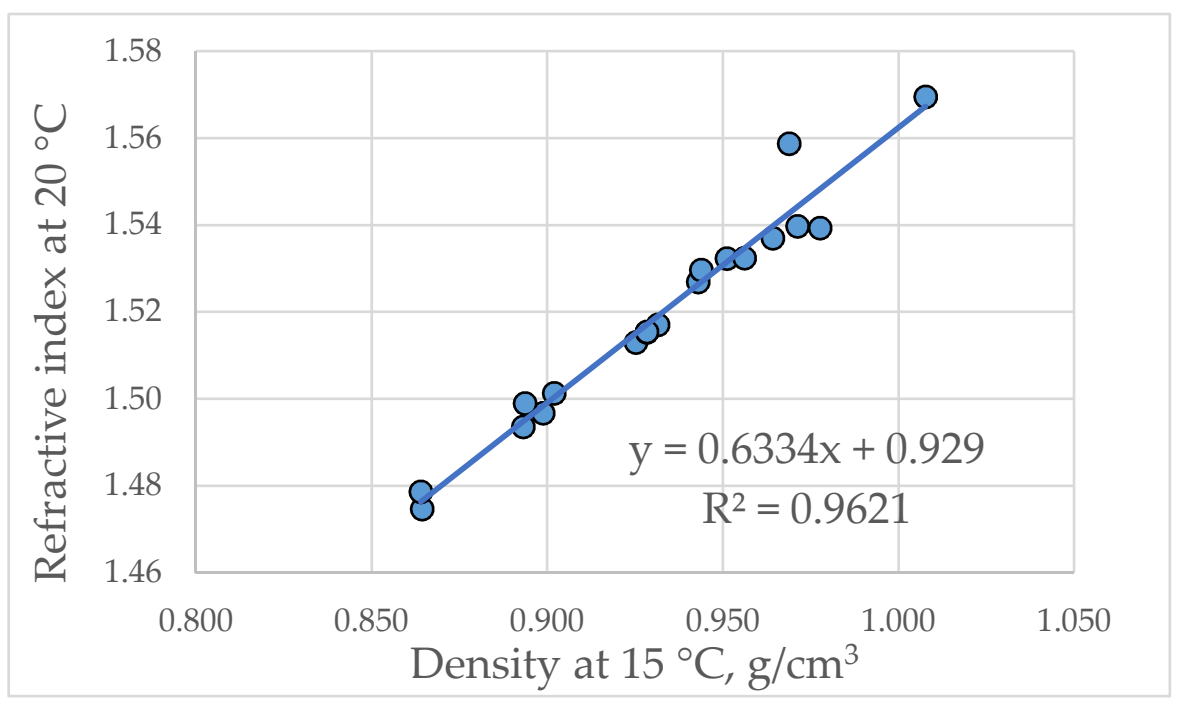

(b)

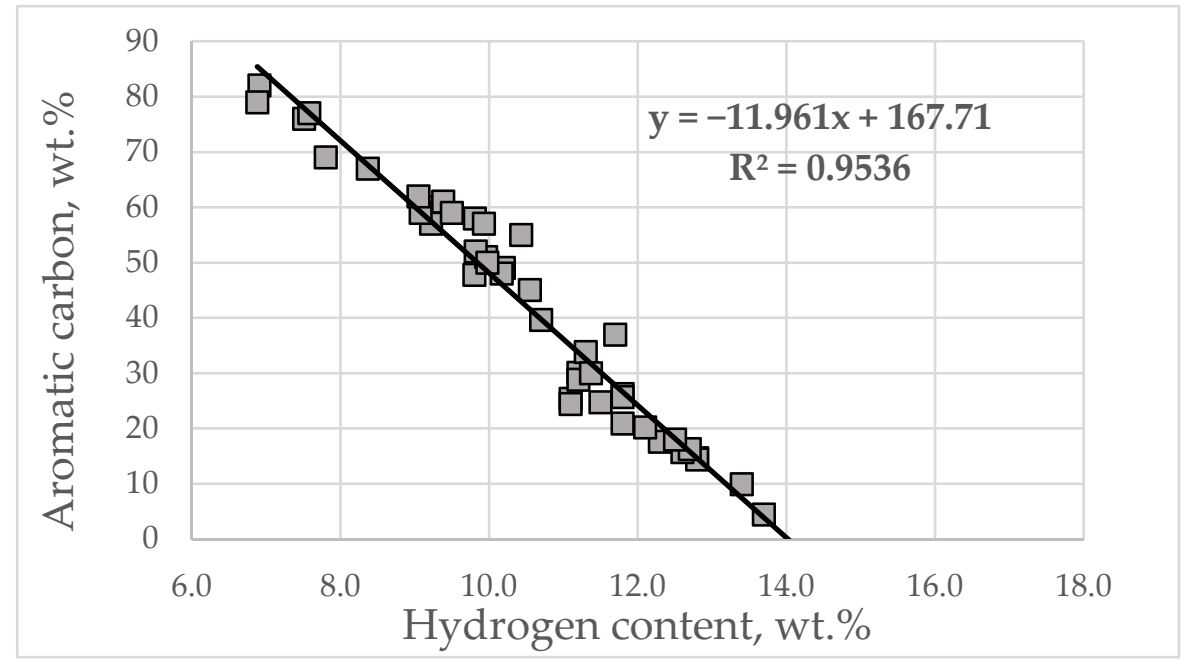

(c)

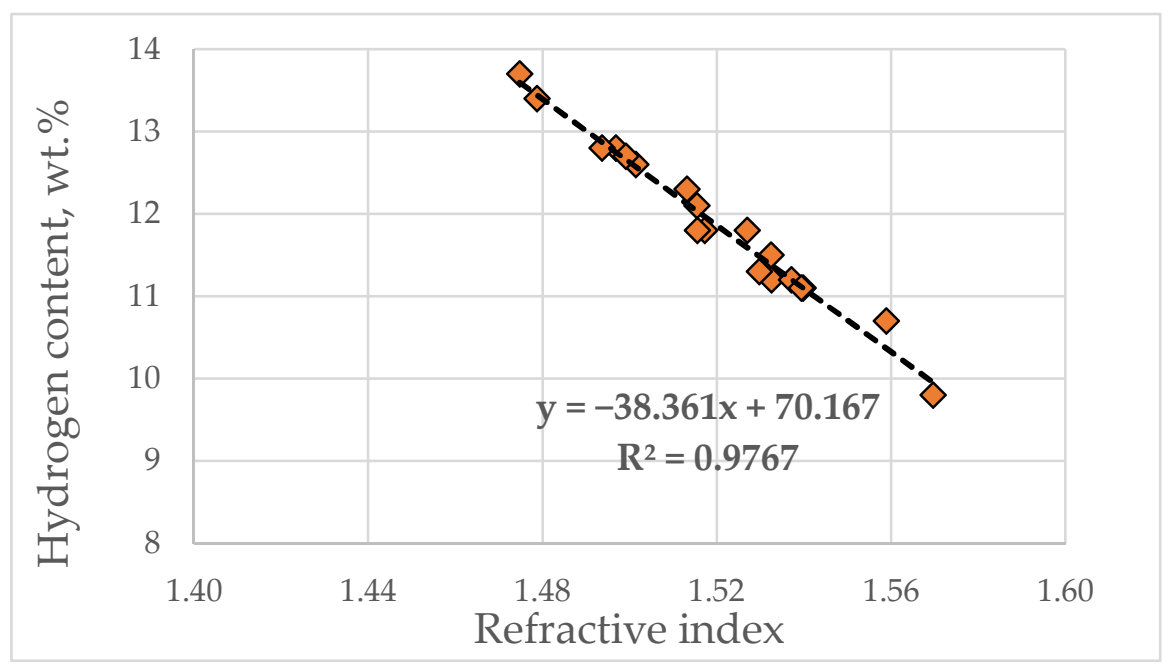

(d)

Figure 1. Strong correlations between density and hydrogen content (a) and refractive index (b), between hydrogen and aromatic carbon contents (c) and between refractive index and hydrogen content $(\mathbf{d})$. 
Table S5 from Supplementary material exhibits a comparison between the measured and predicted hydrogen content in VGOs of different origins by the empirical correlations studied in this work. It is evident from these data that the average absolute deviation increases in the order: $(H, C O P$ correlation; Equation (16); $\mathrm{AD}=0.05 \mathrm{wt} . \%)<($ Figure $1 \mathrm{~d}$; $\mathrm{AD}=0.11 \mathrm{wt} . \%)<(H$, Dhulesia; Equation $(16) ; \mathrm{AD}=0.34 \mathrm{wt} . \%)<(H$, Goosens, Equation (22); $\mathrm{AD}=0.43$ wt. $\%$ ). It could be concluded here again that density and $T_{50 \%}$ are the VGO characteristics that best describe the hydrogen content.

The data from Table S1 from Supplementary material were used to develop two more correlations of predictions of VGO aromatic carbon content, by employing multiple linear regression. They are summarized below as Equations (29) and (30):

$$
\begin{gathered}
C_{A}=168.2-11.2109 H-0.02552 M W R^{2}=0.981 \\
C_{A}=-245.8-0.07053 T_{50}+325.6533 d_{15} \mathrm{R}^{2}=0.966
\end{gathered}
$$

The property range for Equations (29) and (30) are as follows: $C_{A}=4.4$ to $82 \mathrm{wt} . \%$; $H=6.88$ to 13.7 wt. $\% ; d_{15}=0.864$ to $1.102 \mathrm{~g} / \mathrm{cm}^{3} ; T_{50 \%}=369$ to $690{ }^{\circ} \mathrm{C}$.

Table S6 from Supplementary material shows a comparison between measured and predicted aromatic carbon content by the empirical correlations of Dhulesia [25] and Choudhary (COP) [21], Figure 1c, Equations (32) and (33). These data show that the average absolute deviation increases in the order: (Equation (32); $\mathrm{AD}=2.1 \mathrm{wt} . \%$ ) $<$ (Equation (33); $\mathrm{AD}=2.8$ wt. $\%)<($ Figure $1 \mathrm{c} ; \mathrm{AD}=3.1 \mathrm{wt} . \%)<(\mathrm{COP}$, Equation $(23) ; \mathrm{AD}=3.4 \mathrm{wt} . \%)<($ Dhulesia; Equation (15); $\mathrm{AD}=7.5 \mathrm{wt} . \%)$. The most accurate is the prediction of $\mathrm{VGO} C_{A}$ content from the information on the hydrogen content, the molecular weight and Equation (32), followed by information on the density and $T_{50 \%}$ and Equation (33). Here, again the significance of density and $T_{50 \%}$ of VGO for its characterization is highlighted by modeling the aromatic carbon content prediction.

Table 3 summarizes the range of variation of the contents of aromatic carbon, hydrogen, paraffinic carbon, naphthenic carbon, aromatic parts, naphthenic parts, paraffinic parts and aromatic ring index. It is worth noting here that the $\mathrm{n}-\mathrm{d}-\mathrm{M}$ method reports negative values for aromatic carbon (DQ-VGO, sample Nr.40 from Table S1 from Supplementary material), naphthenic carbon contents (Visbroken, sample Nr.18 from Table S1 from Supplementary material), the API method reports a negative value for the content of paraffinic parts (DQ-VGO, sample Nr.40 from Table S1 from Supplementary material); (DG-CGO, sample Nr.41) and (FCC SLO (CLO-15), sample Nr. 56). These findings support the reasoning of Choudhary and Meier [21] that the n-d-M method and API procedure, due to their development being based mainly on data for lower boiling factions, are expected to be less accurate. Nevertheless, the $n-d-M$ method has been used in several studies on the reactivity of FCC feedstocks to characterize the heavy oils $[5,7,47,48]$. The data from this study suggest that the n-d-M method and API procedure cannot be employed for the characterization of the whole range of investigated vacuum gas oils, because a negative value for the content of any component has no physical meaning. All three methods for the prediction of aromatic carbon content, as well as the ARI, report negative values. It was found that the negative value for the aromatic carbon content and ARI is reported for the DQ-VGO [36] (see Table S2 from Supplementary material). However, if we calculate the number of carbon and hydrogen atoms employing the formulas (31) and (32) we can get the following empirical composition for DQ-VGO- $-\mathrm{C}_{30} \mathrm{H}_{66}$.

$$
\begin{aligned}
N_{C} & =\frac{\text { Carbon content }}{100} * \frac{M W}{12} \\
N_{H} & =\frac{\text { Hydrogen content }}{100} * \frac{M W}{1}
\end{aligned}
$$


Table 3. Range of variation in the empirically predicted VGO characterizing parameters.

\begin{tabular}{lcc}
\hline & Min & Max \\
\hline $\mathrm{C}_{\mathrm{A}}$ (ndM) & -34.2 & 84.2 \\
$\mathrm{C}_{\mathrm{N}}$ (ndM) & -6.2 & 70.7 \\
$\mathrm{C}_{\mathrm{P}}$ (ndM) & 11.0 & 66.2 \\
$\mathrm{P}(\mathrm{API})$ & -31.1 & 75.3 \\
$\mathrm{~N}(\mathrm{API})$ & 4.9 & 88.0 \\
$\mathrm{~A}(\mathrm{API})$ & 3.5 & 45.2 \\
Hydrogen content, wt. (Goosens) & 7.2 & 17.8 \\
Hydrogen content, wt.\% (COP) & 6.3 & 15.2 \\
$\mathrm{C}_{\mathrm{A}}$, wt.\% (COP) & -12.4 & 108.7 \\
ARI & -1.6 & 3.6 \\
\hline
\end{tabular}

This empirical composition for DQ-VGO is very close to that of Triacontane $\left(\mathrm{C}_{30} \mathrm{H}_{62}\right)$ whose physical properties like density $=0.81 \mathrm{~g} / \mathrm{cm}^{3}$, molecular weight $=423 \mathrm{~g} / \mathrm{mol}$ [49] and boiling point $450{ }^{\circ} \mathrm{C}$ ) are very close to those of DQ-VGO (density $=0.801 \mathrm{~g} / \mathrm{cm}^{3}$ and molecular weight $=426 \mathrm{~g} / \mathrm{mol}$ (see Table S1 from Supplementary material)). Based on these facts one may suggest that the saturate content of DQ-VGO should be $100 \%$, and the content of aromatic carbon should be zero. Instead, the reported content of saturates for the DQ-VGO is $83.0 \mathrm{wt}$.\%. In our earlier researches [44,45] we employed the non-linear least squares method to model the function of aromatic structure contents of vacuum residual oils and crude oils from density. In this way, the density at zero aromatic structure content was modeled for the vacuum residual oils and crude oils. The model developed was used as a tool for detecting incorrect results from SARA analysis of vacuum residual oils [44]. We decided to apply the same approach to model the dependence of aromatic structure content on the density of vacuum gas oils using another set of data for density and aromatic structure (aromatics + resins + asphaltenes fractions) content of 144 VGOs taken from the literature source [50]. This data set is given in Table S3 from Supplementary material and covers VGOs having density $=0.8521$ to $1.1279 \mathrm{~g} / \mathrm{cm}^{3}$ and aromatic structure content $=9.3$ to $99.2 \mathrm{wt} . \%$. These data were processed by the non-linear least squares method to construct the function $\mathrm{f}_{1}$ of VGO aromatic structure content from the VGO density such that:

- The function $f_{1}$ is monotonically increasing.

- There exists a point $x_{0}$ in the interval $\left[0.8,0.9 \mathrm{~g} / \mathrm{cm}^{3}\right]$ such that $f_{1}\left(x_{0}\right)=0$ (aromatic structure content $=0$ ). (This interval was defined by the value for density of triacontane $\left(\mathrm{C}_{30} \mathrm{H}_{62}\right)$.

- $\quad f_{1}(x)<100$ for all $x \in\left[x_{-} 0, \infty\right]$.

- The function $f_{1}$ approximates data $x_{\mathrm{i}}$ (density), $y_{\mathrm{i}}$ (aromatic structure content) from the data in Table S3 from Supplementary material (mentioned above).

As model function $f_{1}$ we consider logistic function in the form

$$
f_{1}\left(x ; a_{1}, b_{1}, c_{1}, d_{1}\right)=\frac{100}{c_{1}+a_{1} \exp \left(-b_{1} x\right)}-d_{1}
$$

Here $a_{1}, b_{1}, c_{1}$ and $d_{1}$ are constant. Let us set ( $x_{0}$ is any real number)

$$
d_{1}=\frac{100}{c_{1}+a_{1} \exp \left(-b_{1} x_{0}\right)}
$$

Then, obviously $f_{i}\left(x_{0}\right)=0$.

Therefore, we have to solve the following min-min problem

$$
\begin{gathered}
\min _{x_{0}}\left\{\min _{a_{1}, b_{1}, c_{1}}\left\{\sum_{i=1}^{107}\left(y_{i}-f_{1}\left(x_{i}\right)\right)^{2}\right\}+\min _{a_{2}, b_{2}, c_{2}}\left\{\sum_{i=1}^{21}\left(y_{i}-f_{2}\left(x_{i}\right)\right)^{2}\right\}\right. \\
\left.+\min _{a_{3}, b_{3}, c_{3}}\left\{\sum_{i=1}^{20}\left(y_{i}-f_{3}\left(x_{i}\right)\right)^{2}\right\}\right\}
\end{gathered}
$$

We use the computer algebra system Maple (and GlobalOptimization Toolbox) to solve numerically the obtained non-linear min-min problem. As a global search algorithm, we used a differential evolution method, see [51] and references therein. 
The following expression was obtained for the VGO aromatic structure content dependence on VGO density for the data from Table S3 from Supplementary material (Equation (36)):

$$
A R O=\frac{100}{0.4426+547.9 \mathrm{e}^{-8.719} \mathrm{~d}}-113.1
$$

Figure 2a illustrates a graph of the dependence of VGO aromatic structure content on density. The dotted lines are the values predicted by Equation (39) for the aromatic structure contents for the 144 VGOs. The zero content of the aromatic structures obtained from Equation (39) was found to correspond to the VGO density of $0.817 \mathrm{~g} / \mathrm{cm}^{3}$. This value was obtained from the solution of Equation (39). This value is close to the density of Triacontane and therefore could be considered reliable. The data in Figure $2 b$ indicate different shapes of the three curves describing the relationship of density to the aromatic structure content for crude oils, VGOs and vacuum residues at densities lower than $1.02 \mathrm{~g} / \mathrm{cm}^{3}$. Zero aromatic structures were found to correspond to density of $0.750 \mathrm{~g} / \mathrm{cm}^{3}$ for crude oils [45], $0.817 \mathrm{~g} / \mathrm{cm}^{3}$ for VGOs and $0.881 \mathrm{~g} / \mathrm{cm}^{3}$ [44] for vacuum residues. At densities higher than $1.02 \mathrm{~g} / \mathrm{cm}^{3}$ the dependence of aromatic structure content on density becomes equal for the three studied oils: crude oils; VGO and vacuum residue and the slope of increase of aromatic structure content decreases with the enhancement of density. This suggests that the augmentation of density at a value above $1.02 \mathrm{~g} / \mathrm{cm}^{3}$ is associated with the magnification of the content of the aromatic structures having a higher number of condensed rings, without a significant increase of the total content of aromatic structures. An evaluation of the content of the aromatic structures with a higher number of condensed rings could be obtained by the use of the ARI model [26,27]. The verification of the good fit of ARI to the number of aromatic rings in hydrocarbons and in vacuum gas oils (fluid catalytic cracking slurry oils (FCC SLOs); data taken from Ref. [38]) is illustrated in Figure 3a,b. As apparent from the data in Figure 3b, one sample of FCC SLO deviates from the regression line (Sample Nr 56 from Table S1 from Supplementary material). The same sample exhibited the biggest absolute deviation in aromatic carbon prediction by Equation (15) ( $\mathrm{AD}=21.7 \mathrm{wt} . \%$ (Dhulesia), Equation (23) ( $\mathrm{AD}=15.0 \mathrm{wt} . \%)(\mathrm{COP})$, Equation (29) $(\mathrm{AD}=11.1 \mathrm{wt} . \%)$ and Equation (30) ( $\mathrm{AD}=13.4 \mathrm{wt} . \%)$. This implies some kind of unusual behavior of Sample Nr. 56 that is difficult to explain in this study. Keeping in mind that 100-aromatic structure content equals the saturate content, Equation (36) was used to predict saturate content of the studied VGOs from Table S1 from Supplementary material. Figure 4a shows the agreement between measured and estimated VGO saturate content to be 100 according to Equation (36). The average absolute deviation is $5.6 \mathrm{wt} . \%$ with the biggest absolute deviation observed for $\mathrm{DQ}-\mathrm{VGO}(\mathrm{AD}=24.9 \mathrm{wt} . \%)$. By the use of multiple linear regressions of the data obtained by subtraction from 100\% Equation (36) and the ARI, the following correlation was developed:

$$
\text { VGO Saturates }=-1.867+0.9103(100-A R O)+9.3398 A R I^{-2} R^{2}=0.933
$$
where,

VGO saturates $=\mathrm{VGO}$ saturate content, wt. $\%$;

$A R O=$ VGO aromatic structure content, estimated by Equation (36);

$A R I=$ Aromatic ring index

Equation (37) was developed for the following VGO property range: $d_{15}=0.8010$ to $1.1023 \mathrm{~g} / \mathrm{cm}^{3}$; $\mathrm{ARI}=-1.6$ to 3.6 ; saturate content $=0.8$ to $90.1 \mathrm{wt} . \%$.

Figure $4 \mathrm{~b}$ presents the agreement between the measured and calculated VGO saturate contents by Equation (37). It is evident from the data in Figure 1 that Equation (37) predicts the VGO saturate content better (average absolute deviation of $4.1 \mathrm{wt} . \%$ ) than Equation (36). This could be ascribed to the inclusion of ARI in the regression implying that the ARI is an important parameter in the characterization of VGOs. Table S7 from Supplementary material presents detailed data on the measured and predicted VGO saturate contents by Equations (36) and (37) and their absolute deviations. Considering that the reproducibility of measurement of the saturate content of heavy oils according to ASTM D 2007 is $7.8 \mathrm{wt} . \%$ [52], one can see that four predictions out of 37 are outside of that limit for 
Equation (40) (10.8\%). For Equation (36), the predictions outside of the reproducibility limit for VGO saturate content measurement are eight. However, if we assume that saturate content in DQ-VGO is $100 \%$, due to the reasons explained beforehand, the number of predictions falling outside the reproducibility limit would become three out of 37 (8.1\%). The verification of the correctness of measurement of saturate content of FCC SLO (sample $\mathrm{Nr} 57$ from Table S1 from Supplementary material) by juxtaposing its hydrogen content against the relation established for FCC slurry oils (data extracted from Ref. [38]), shown in Figure S1, indicates that this FCC SLO should have saturate content of $19 \mathrm{wt} . \%$. This value almost completely coincides with that predicted by Equation (37) - $19.4 \mathrm{wt} . \%$. Therefore, an assumption can be made that the saturate content of FCC SLO (sample Nr 57 from Table S1 from Supplementary material) might be wrong.

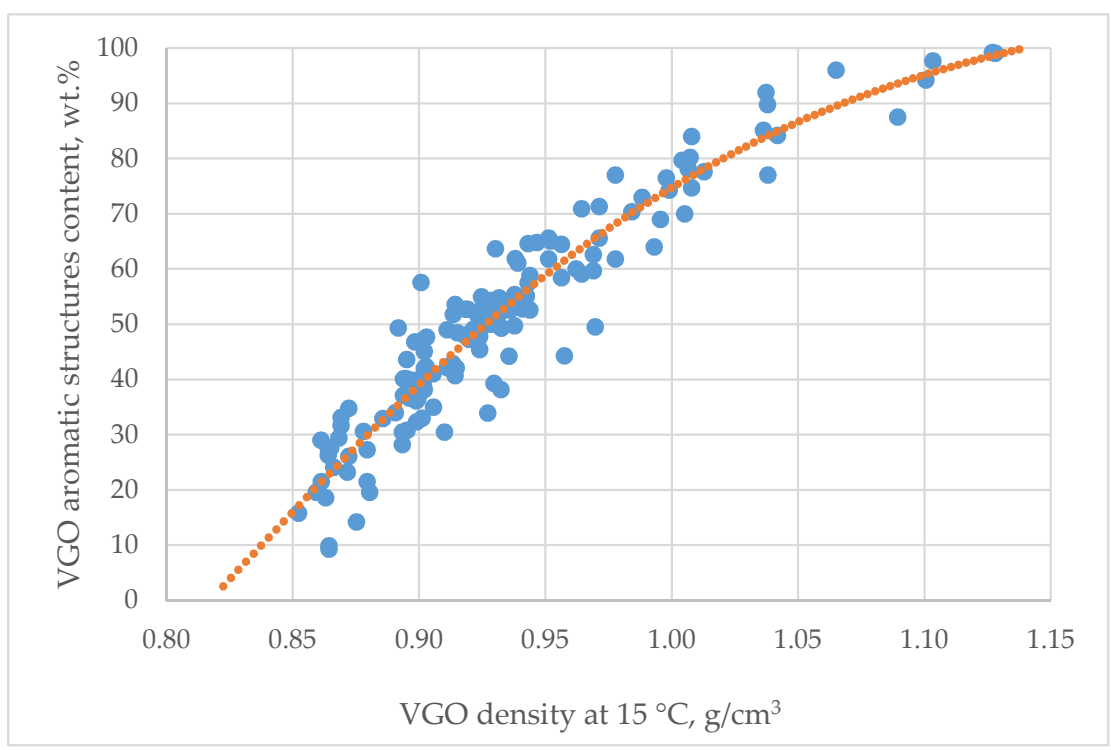

(a)

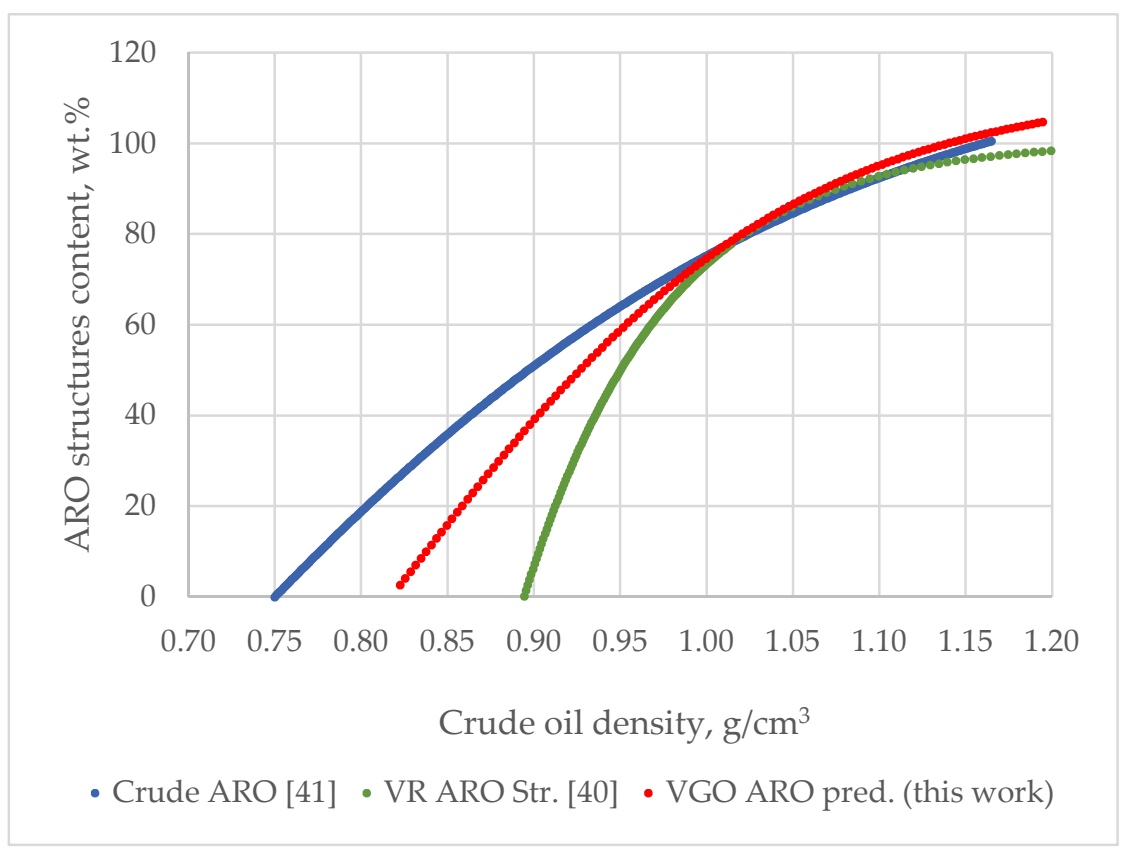

(b)

Figure 2. Dependence of the VGO aromatic structure (aromatic, resin + asphaltene fractions) content on VGO density (a) and dependence of aromatic structure content on crude oils, vacuum residual oils and VGO predicted by the use of the non-linear least squares method and reported in [40,41] (b). 


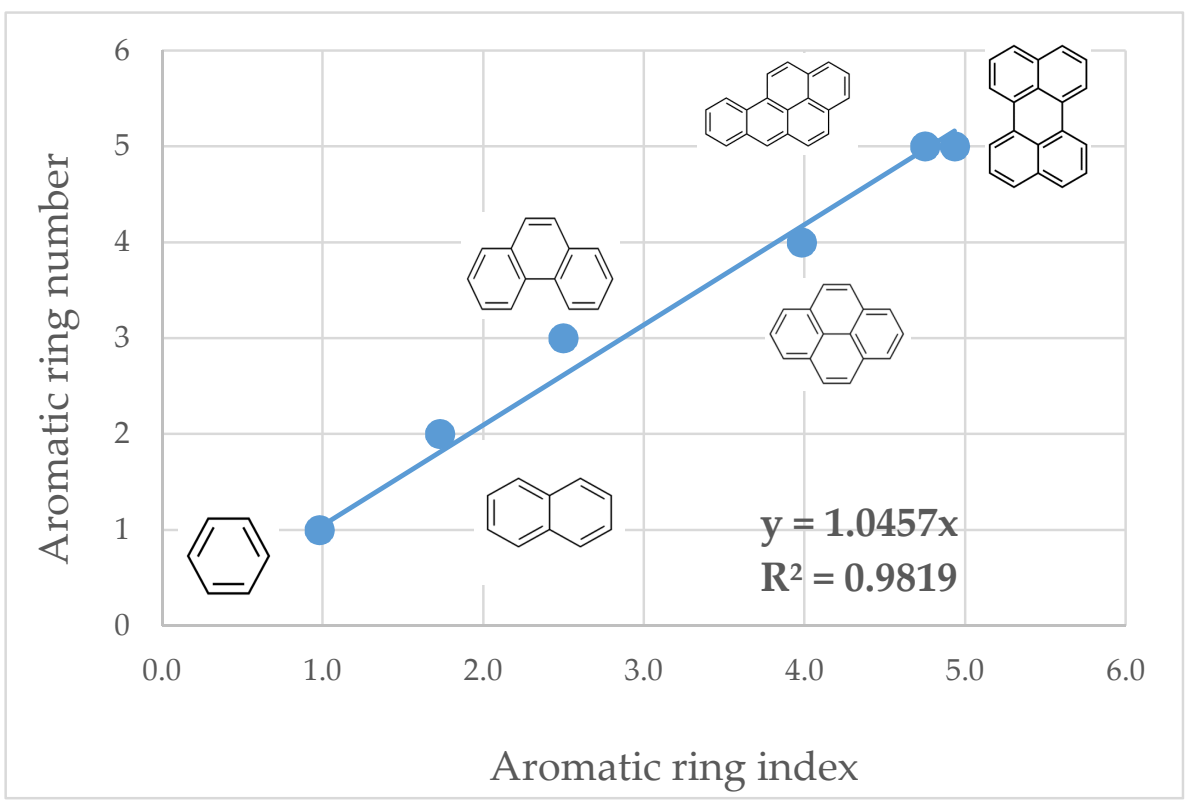

(a)

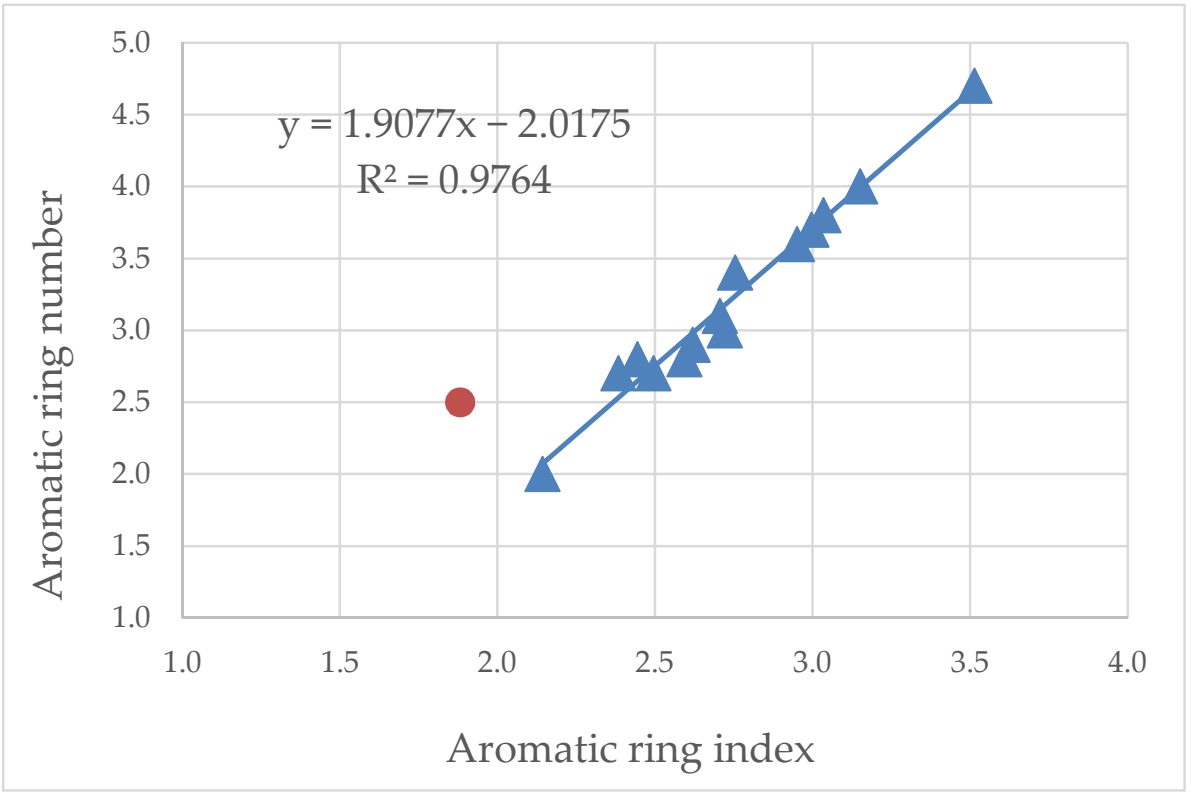

(b)

Figure 3. A comparison between the estimated by Equation (25) [26,27] aromatic ring index (ARI) and the actual aromatic ring numbers of benzene, naphthalene, phenantrene, pyrene, benze(a)pyrene and perylene (a) and a comparison between estimated ARI and the average aromatic ring numbers of fluid catalytic cracking slurry oils measured by NMR analysis (data taken from Ref. [38]) (b) Reprinted with permission from [Mondal, S.; Yadav, A.; Kumar, R.; Bansal, V.; Das, S.K.; Christopher, J.; Kapur, G.S. Molecular-level structural insight into clarified oil by nuclear magnetic resonance (NMR) spectroscopy: Estimation of hydrocarbon types and average structural parameters. Energy Fuels 2017, 31, 7682-7692, doi:10.1021/acs.energyfuels.7b00994.] Copyright [2017, AMERICAN CHEMICAL SOCIETY/COPYRIGHT AMERICAN CHEMICAL SOCIETY]. 


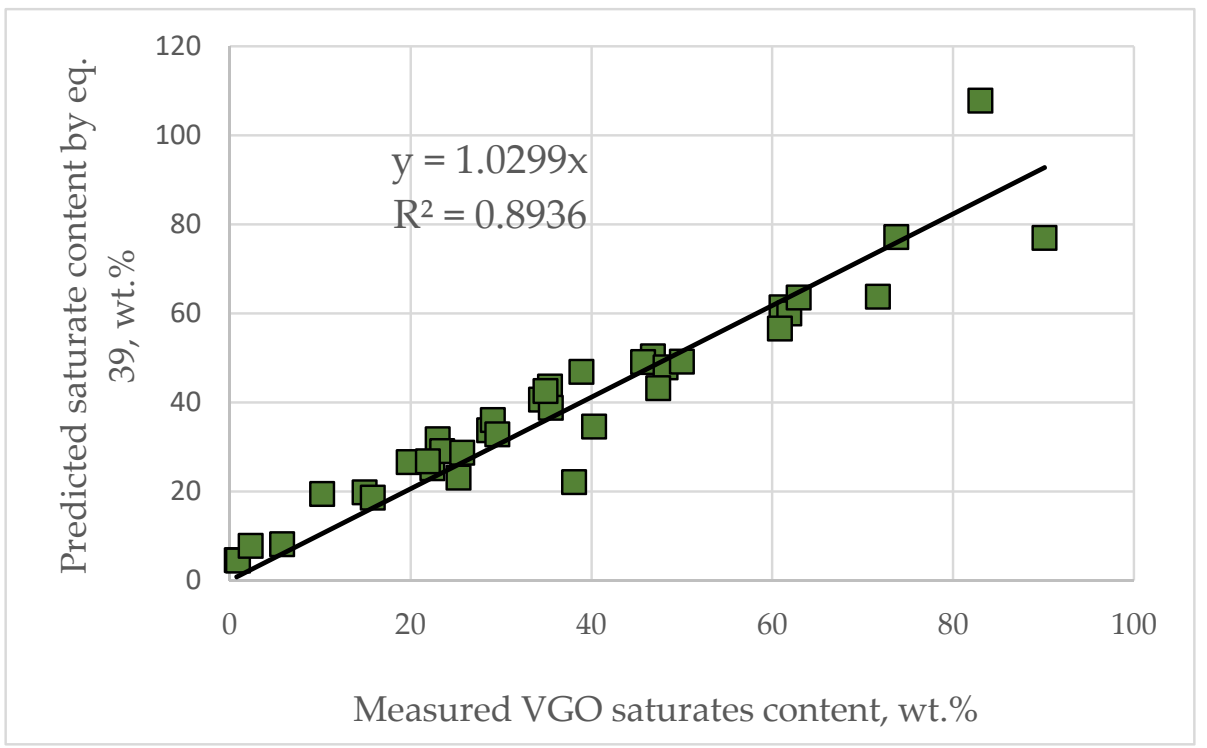

(a)

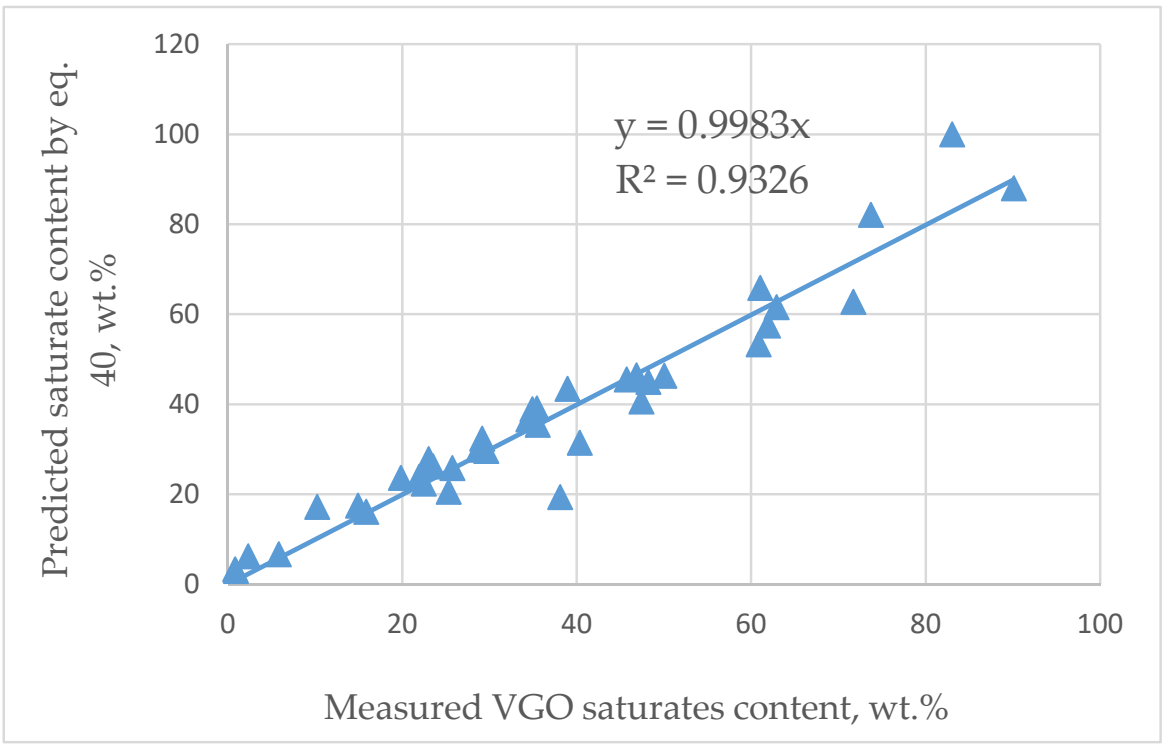

(b)

Figure 4. Agreement between predicted and measured saturate content by Equation (36) (a) and by Equation (37) (b).

Concerning the heavy aromatic content (tri + condensed aromatics) prediction it was found that it correlates with the aromatic carbon content. However, two VGO groups were identified to obey different dependencies: the FCC slurry oils and the remaining VGOs. Figure 5 a indicates the relationship between aromatic carbon content and heavy aromatic content for FCC slurry oils, which is described by a second-order polynomial. Figure $5 b$ exhibits the relationship between aromatic carbon content and heavy aromatic content for VGOs different from FCC slurry oils, which is described by a linear function. The content of heavy aromatics specifies the part of the VGO that, during thermal and catalytic cracking, will define the yield of unconverted VGO, that is, the product with the lowest value as reported in our recent study [53]. 


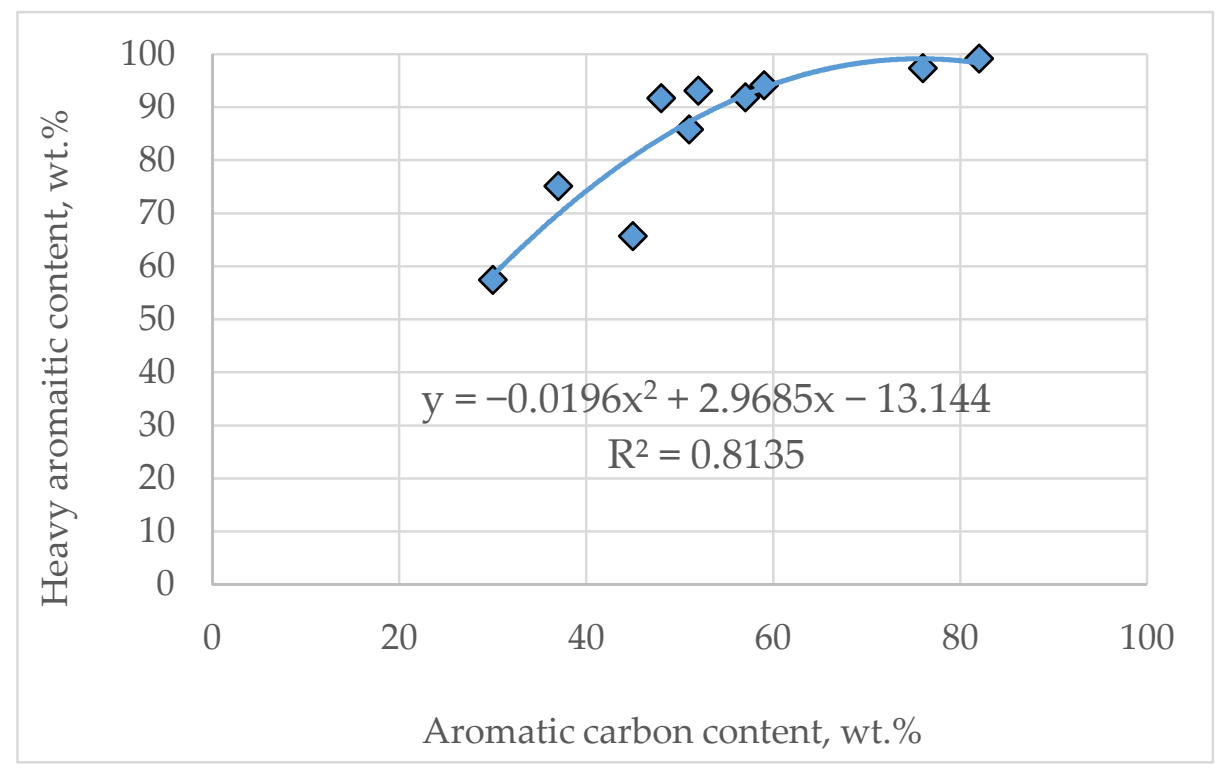

(a)

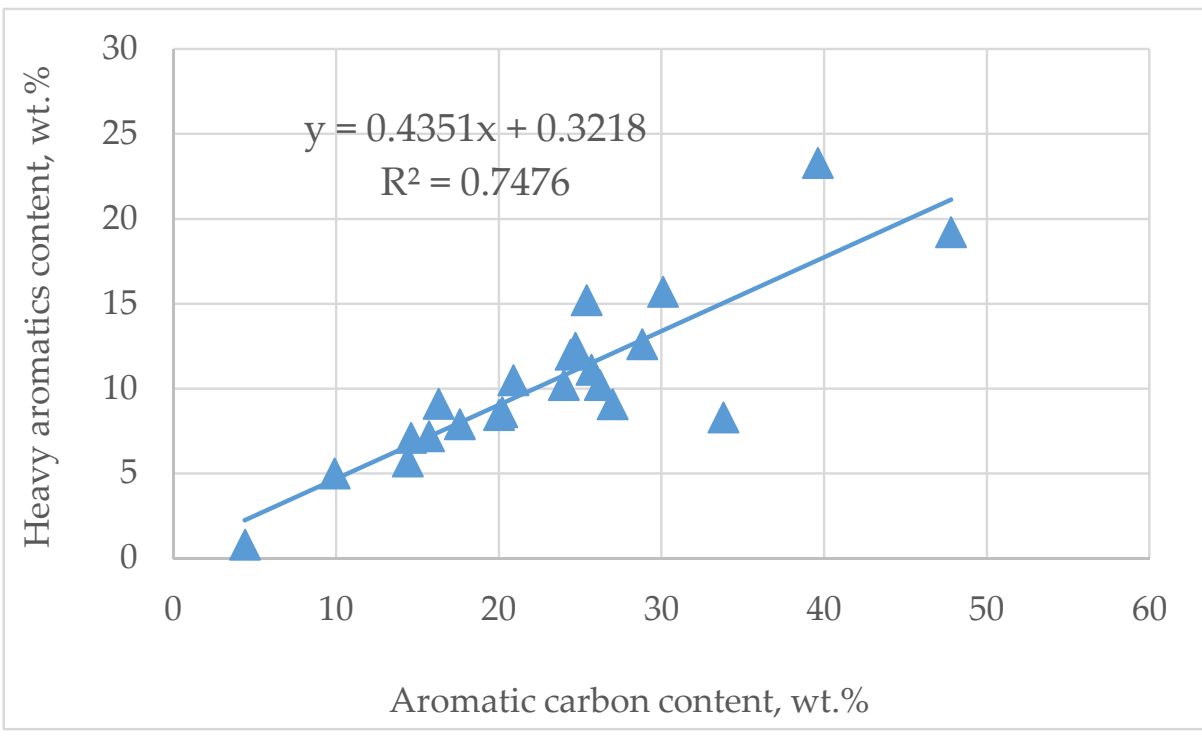

(b)

Figure 5. Dependence of heavy aromatic (tri + condensed aromatics) content on aromatic carbon content for FCC slurry oils (a) and VGOs different from FCC slurry oils (b).

\subsection{Validation of the Developed Model for Prediction of VGO Saturate Content}

Two very different vacuum gas oils: hydrocracked VGO from a hydrocracking unit, which processes Urlas VGO, and FCC slurry oil from LUKOIL Neftohim Burgas refinery were analyzed for their hydrocarbon group composition according to the SARA method described in [54]. Their properties along with the SARA analysis data and estimated saturate contents are summarized in Table 4.

The FCC slurry oil sample was initially analyzed for the determination of the SARA composition by the method described in [54] but without using the refractive index for specifying the separation between saturates and aromatics. This way of action in measuring the SARA composition of heavy oils was also practiced in our earlier study [55] in order to shorten the time for the performance of SARA analysis from four to three days. The saturate content predicted by Equation (40) and that of the first FCC SLO SARA analysis exhibited a difference of $38.6 \mathrm{wt} . \%$, which was far from the repeatability limit of $\pm 2 \mathrm{wt} . \%$ for this method. Another SARA analysis of this FCC SLO was performed and the difference 
between the saturate content predicted by Equation (37) and that of the second FCC SLO SARA analysis was already within the repeatability limit (1.4 wt.\%). In the second SARA analysis of that FCC SLO, the separation between saturates and aromatics was identified by refractive index measurement as described in [54]. The difference between the measured and estimated by Equation (37) saturate contents of the hydrocracked VGO was also within the repeatability limit (-1.5 wt.\%). This is an indicator that Equation (40) can be used to predict VGO saturate content from density, molecular weight and refractive index and also for the verification of the correctness of the performance of the SARA analysis. In the case of missing data for the molecular weight or refractive index $T_{50 \%}$, Equation (30) can be used to estimate the refractive index and the molecular weight reported by the correlations reported in [23,56,57].

Table 4. Properties of hydrocracked VGO and FCC SLO not included in the data from Table S1 from Supplementary material.

\begin{tabular}{|c|c|c|c|}
\hline Properties & Hydrocracked VGO & $\begin{array}{c}\text { FCC SLO (1st } \\
\text { SARA Analysis) }\end{array}$ & $\begin{array}{c}\text { FCC SLO (2nd } \\
\text { SARA Analysis) }\end{array}$ \\
\hline Density at $15^{\circ} \mathrm{C}(\mathrm{g} / \mathrm{mL})$ & 0.8520 & \multicolumn{2}{|c|}{1.0826} \\
\hline$T_{50 \%},{ }^{\circ} \mathrm{C}$ & 425 & \multicolumn{2}{|c|}{401} \\
\hline Refractive index at $20^{\circ} \mathrm{C}$ & 1.4731 & \multicolumn{2}{|c|}{1.6349} \\
\hline Molecular weight, g/mol & 350 & \multicolumn{2}{|c|}{250} \\
\hline Aromatic ring index $(26,27)$ & 0.67 & \multicolumn{2}{|c|}{3.00} \\
\hline \multicolumn{4}{|l|}{ Hydrocarbon group composition, wt.\% } \\
\hline Saturates & 93.1 & 44.5 & 7.3 \\
\hline Total aromatics & & 50.3 & 5.8 \\
\hline Light aromatics & 2.5 & & 0.7 \\
\hline Middle aromatics & 2.4 & & 12.3 \\
\hline Heavy aromatics & 0.9 & & 75.8 \\
\hline Resins & 1.1 & 2.7 & 2.1 \\
\hline Asphaltenes & 0 & 2.5 & 1.8 \\
\hline Estimated by Equation (40) saturates content, wt.\% & 94.6 & 5.9 & 5.9 \\
\hline $\begin{array}{l}\text { Deifference between measured and predicted by } \\
\text { Equation (40) saturates content, wt.\% }\end{array}$ & -1.5 & 38.6 & 1.4 \\
\hline
\end{tabular}

The characterization of petroleum fractions by empirical models, which relate the oil bulk physicochemical properties to the content of important structural parameters, has been developed for the last 70 years (from 1951 [41] with the n-d-M method to 2021 with ARI [27]. They have proved their usefulness in predicting VGO reactivity and product selectivity in the processes of catalytic and thermal cracking $[5,7,17,47,48]$ and in the modeling of the most complex petroleum compounds-the asphaltenes [27]. Over the years improvement in the predictions of the content of the VGO characterizing parameters has been registered $[19,21]$. It has also been shown that the empirical models are capable of predicting VGO compound content in [31] and in this work. Unfortunately, the empirical models can prove their accuracy in prediction for the property range of variation for which they have been developed but outside of this range, a failure in the prediction is possible because the type of the mathematical expressions can be different for the new property range. This was also observed in this work, registering negative values for DQ-VGO aromatic carbon content and ARI. This implies that further improvement in the predictions is required by widening the range of property variation and involving new characterizing factors and possibly new mathematical techniques.

\section{Conclusions}

The structural information about vacuum gas oils with a very wide range of variation of saturate content between 0.8 and $93.1 \mathrm{wt} . \%$ can be obtained by empirical models and a combination of two main physicochemical properties: density and $T_{50 \%}$. From these properties refractive index, molecular weight, hydrogen and aromatic carbon contents, 
the number of aromatic rings in the average molecular structure and saturate content can be derived.

- The aromatic ring index developed by Abutiqiya et al. [26,27] was confirmed to properly predict the actual aromatic ring numbers of individual hydrocarbons and fluid catalytic cracking slurry oils characterized by NMR.

- The use of a logistic function and employment of nonlinear least squares method along with ARI allows prediction of the VGO saturate content by the newly developed correlation in this work.

- The content of heavy aromatics was found to correlate with the aromatic carbon content.

- The dependence of heavy aromatic content on the aromatic carbon content was found to differentiate between FCC slurry oils and other VGOs.

- The relationship of aromatic carbon content with heavy aromatic content for FCC slurry oils can be predicted by a second-order polynomial, while that of the remaining VGOs can be predicted by a linear function.

- The empirical models developed in this study can be used not only for obtaining the valuable structural information necessary to predict the behavior of the VGOs in the conversion processes but can also be applied for the detection of incorrectly performed SARA analyses.

- In the current study, it was shown that the two physical properties, density and $T_{50 \%}$, and the ARI estimated on their base along with empirical modeling are capable of predicting the contents of saturates and heavy poly-nuclear (tri-nuclear plus) aromatics in vacuum gas oils with reasonable accuracy.

Supplementary Materials: The following are available online at https: / www.mdpi.com/article / 10.3390/resources10070071/s1, Figure S1: Relation of fluid catalytic cracking slurry oil hydrogen content to saturates content, Table S1: Properties of the vacuum gas oils under study, Table S2: Empirically modeled characterizing parameters of the vacuum gas oils under study, Table S3: Data for density at $15{ }^{\circ} \mathrm{C}$ and content of aromatic structures (aromatic, resin, and asphaltene fractions) in 144 vacuum gas oils, Table S4: Comparison between measured and predicted by the empirical correlations refractive index of VGO from different origin, Table S5: Comparison between measured and predicted by the empirical correlations hydrogen content in VGO from different origin, Table S6: Comparison between measured and predicted by the empirical correlations aromatic carbon content in VGO from different origin, Table S7: Comparison between measured and predicted by the empirical correlations saturates content in VGO from different origin.

Author Contributions: Conceptualization, E.S.; Data curation, R.K.D. and S.N.; Formal analysis, I.P.P. and D.Y.; Investigation, I.V.K. and L.T.-Y.; Methodology, S.S.; Software, V.A., S.R. and D.D.S.; Supervision, K.A.; Writing-original draft, D.S.S. and I.K.S. Writing-revised manuscript D.S.S. and K.Z. All authors have read and agreed to the published version of the manuscript.

Funding: This research was funded by Asen Zlatarov University-Burgas, Project: Information and Communication Technologies for a Digital Single Market in Science, Education and Security DCM \# 577/17.08.2018 (2018-2021).

Institutional Review Board Statement: Not applicable.

Informed Consent Statement: Not applicable.

Data Availability Statement: Not applicable.

Acknowledgments: The authors are grateful for the support provided by the Bulgarian Ministry of Education and Science under the National Research Programme "Information and Communication Technologies for a Digital Single Market in Science, Education and Security" approved by DCM \# 577/17.08.2018.

Conflicts of Interest: The authors declare no conflict of interest.

\section{Abbreviations}

List of symbols and abbreviations used 


$\begin{array}{ll}A P I & \text { API gravity } \\ A R I & \text { Aromatic ring index } \\ C & \text { Carbon content, wt. \% } \\ C_{A} & \text { Aromatic carbon content, } \% \\ C H & \text { Carbon to hydrogen ratio } \\ C_{N} & \text { Naphthenic carbon content, \% } \\ C p & \text { Paraffinic carbon content, \% } \\ d & \text { Density at } 20^{\circ} \mathrm{C}, \mathrm{g} / \mathrm{cm}^{3} \\ d_{15} & \text { Density at } 15^{\circ} \mathrm{C}, \mathrm{g} / \mathrm{cm}^{3} \\ F R I & \text { Function of refractive index } \\ \text { FCC SLO } & \text { Fluid catalytic cracking slurry oil } \\ H & \text { Hydrogen content, wt. } \% \\ I & \text { Refractive index parameter } \\ K w & \text { Watson K factor } \\ m, v, w, C_{R} & \text { Parameters } \\ M W & \text { Molecular weight } \\ n_{D 20} & \text { Refractive index at } 20^{\circ} \mathrm{C} \\ R I & \text { Refractive index at } 2{ }^{\circ} \mathrm{C} \\ S & \text { Sulfur content, wt. } \% \\ S G & \text { Specific gravity } \\ T_{\mathrm{b}} & \text { Normal boiling point or } 50 \text { wt. } \% \text { TBP, } \mathrm{K} \\ T_{50} & 50 \% \text { boiling point, }{ }^{\circ} \mathrm{C} \\ T_{50} \mathrm{~F} & 50 \% \text { boiling point, }{ }^{\circ} \mathrm{F} \\ \text { VGO } & \text { Vacuum gas oil } \\ V I S & \text { Viscosity at } 98.9{ }^{\circ} \mathrm{C}\left(210{ }^{\circ} \mathrm{F}\right), \mathrm{cSt} \\ & \end{array}$

\section{References}

1. Alabdullah, M.A.; Gomez, A.; Vittenet, J.; Bendjeriou-Sedjerari, A.; Xu, W.; Abba, I.; Gascon, J. A viewpoint on the refinery of the future: Catalyst and process challenges. ACS Catal. 2020, 10, 8131-8140. [CrossRef]

2. Ng, S.H.; Wang, J.; Fairbridge, C.; Zhu, Y.; Yang, L.; Ding, F.; Yui, S. Study of Canadian FCC feeds from various origins and treatments. 1. Ranking of feedstocks based on feed quality and product distribution. Energy Fuels 2004, 18, 160-171. [CrossRef]

3. Fisher, I.P. Effect of feedstock variability on catalytic cracking yields. Appl. Catal. 1990, 65, 189-210. [CrossRef]

4. Billaud, F.; Berthelin, M.; Freund, E. Thermal cracking of vacuum distillates. J. Anal. Appl. Pyrolysis 1986, 10, 139-151. [CrossRef]

5. Bollas, G.M.; Vasalos, I.A.; Lappas, A.A.; Iatridis, D.K.; Tsioni, G.K. Bulk molecular characterization approach for the simu-lation of FCC feedstocks. Ind. Eng. Chem. Res. 2004, 43, 3270-3281. [CrossRef]

6. Stratiev, D.; Galkin, V.; Shishkova, I.; Minkov, D.; Stanulov, K. Yield of products from catalytic cracking of vacuum gasoils. Chem. Technol. Fuels Oils 2007, 43, 311-318. [CrossRef]

7. Stratiev, D.; Shishkova, I.; Ivanov, M.; Dinkov, R.; Georgiev, B.; Argirov, G.; Atanassova, V.; Vassilev, P.; Atanassov, K.; Yordanov, D.; et al. Catalytic cracking of diverse vacuum residue hydrocracking gas oils. Chem. Eng. Technol. 2021, 44, 997-1008. [CrossRef]

8. Nazarova, G.; Oreshina, A.; Kaliyev, T.; Arkenova, S.; Antonov, A.; Lemeshko, E. Development of a formalized scheme of hydrocarbon transformations in the catalytic cracking for forecasting the individual composition of gases. AIP Conf. Proc. 2020, $2285,020014$.

9. Ivanchina, E.D.; Ivashkina, E.N.; Nazarova, G.Y.; Seitenova, G.Z. Influence of feedstock group composition on the octane number and composition of the gasoline fraction of catalytically cracked vacuum distillate. Pet. Chem. 2018, 58, 225-236. [CrossRef]

10. Ivanchina, E.; Ivashkina, E.; Nazarova, G. Mathematical modelling of catalytic cracking riser reactor. Chem. Eng. J. 2017, 329, 262-274. [CrossRef]

11. Nazarova, G.; Ivashkina, E.; Ivanchina, E.; Oreshina, A.; Dolganova, I.; Pasyukova, M. Modeling of the catalytic cracking: Catalyst deactivation by coke and heavy metals. Fuel Process. Technol. 2020, 200. [CrossRef]

12. Nazarova, G.; Ivashkina, E.; Ivanchina, E.; Oreshina, A.; Vymyatnin, E. A predictive model of catalytic cracking: Feedstockinduced changes in gasoline and gas composition. Fuel Process. Technol. 2021, 217, 106720. [CrossRef]

13. Nazarova, G.Y.; Ivashkina, E.N.; Oreshina, A.A.; Vymyatnin, E.K.; Seytenova, G.Z.; Burumbaeva, G.R. Vacuum distillate catalytic cracking technology modelling: Feedstock and products composition and properties investigation. Pet. Coal 2020, 62, 380-389.

14. Nazarova, G.; Ivashkina, E.; Ivanchina, E.; Vosmerikov, A.; Vosmerikova, L.; Antonov, A. A model of catalytic cracking: Product distribution and catalyst deactivation depending on saturates, aromatics and resins content in feed. Catalysts 2021, 11, 701. [CrossRef]

15. Ng, S.H.; Heshka, N.E.; Zheng, Y.; Ling, H.; Wang, J.; Liu, Q.; Little, E.; Ding, F.; Wang, H. Virgin heavy gas oil from oil sands bitumen as FCC feed. Catalysts 2020, 10, 277. [CrossRef]

16. Stratiev, D.; Shishkova, I.; Veli, A.; Nikolova, R.; Stratiev, D.D.; Mitkova, M.; Yordanov, D. Fluid catalytic cracking and thermal cracking of vacuum gas oils. Effect of feedstock properties on conversion and yields. OGEM 2017, 84-89. [CrossRef] 
17. Stratiev, D.; Minkov, D. Prediction of FCC yields from feedstock quality characterized by empirical methods. Oil Gas Eur. Mag. 2000, 1, 27-32.

18. ASTM International. ASTM International. ASTM D 3238-17a. In Calculation of Carbon Distribution and Structural Group Analysis of Petroleum Oils by the n-d-M Method; ASTM International: West Conshohocken, PA, USA, 2017.

19. Riazi, M.R.; Daubert, T.E. Prediction of molecular-type analysis of petroleum fractions and coal liquids. Ind. Eng. Chem. Res. 1986, 25, 1009-1015. [CrossRef]

20. Riazi, M.R.; Daubert, T.E. Characterization parameters for petroleum fractions. Ind. Eng. Chem. Res. 1987, 26, 755-759. [CrossRef]

21. Choudhary, T.; Meier, P.F. Characterization of heavy petroleum feedstocks. Fuel Process. Technol. 2008, 89, 697-703. [CrossRef]

22. Goossens, A.G. Prediction of the hydrogen content of petroleum fractions. Ind. Eng. Chem. Res. 1997, 36, 2500-2504. [CrossRef]

23. Goossens, A.G. Prediction of molecular weight of petroleum fractions. Ind. Eng. Chem. Res. 1996, 35, 985-988. [CrossRef]

24. Riazi, M.R. Characterization and Properties of Petroleum Fraction; ASTM Manual Series MNL50; ASTM International: Philadelphia, PA, USA, 2005.

25. Dhulesia, H. New correlations predict FCC feed characterizing parameters. Oil Gas J. 1986, 84, 51-54.

26. Abutaqiya, M. Advances in Thermodynamic Modeling of Nonpolar Hydrocarbons and Asphaltene Precipitation in Crude Oils. Ph.D. Thesis, Rice University, Houston, TX, USA, 2019.

27. Abutaqiya, M.I.L.; Alhammadi, A.A.; Sisco, C.J.; Vargas, F.M. Aromatic Ring Index (ARI): A characterization factor for nonpolar hydrocarbons from molecular weight and refractive index. Energy Fuels 2021, 35, 1113-1119. [CrossRef]

28. Modarress, H.; Vakili-Nezhaad, G.R.A. New characterization factor for hydrocarbons and petroleum fluids fractions. Oil Gas Sci. Technol. 2002, 57, 149-154. [CrossRef]

29. Pujro, R.; Falco, M.; Sedran, U. Catalytic cracking of heavy aromatics and polycyclic aromatic hydrocarbons (PAHs) over FCC catalysts. Energy Fuels 2015, 29, 1543-1549. [CrossRef]

30. Abbott, M.M.; Kaufmann, T.G.; Domash, L. A correlation for predicting liquid viscosities of petroleum fractions. Can. J. Chem. Eng. 1971, 49, 379-384. [CrossRef]

31. Stratiev, D.S.; Marinov, I.M.; Shishkova, I.K.; Dinkov, R.K.; Stratiev, D.D. Investigation on feasibility to predict the content of saturate plus mono-nuclear aromatic hydrocarbons in vacuum gas oils from bulk properties and empirical correlations. Fuel 2014, 129, 156-162. [CrossRef]

32. Stratiev, D.; Shishkova, I.; Tankov, I.; Pavlova, A. Challenges in characterization of residual oils. A review. J. Pet. Sci. Eng. 2019, 178, 227-250. [CrossRef]

33. Marques, J.; Maget, S.; Verstraete, J.J. Improvement of ebullated-bed effluent stability at high conversion operation. Energy Fuels 2011, 25, 3867-3874. [CrossRef]

34. Ding, F.; Ng, S.H.; Xu, C.; Yui, S. Reduction of light cycle oil in catalytic cracking of bitumen-derived crude HGOs through catalyst selection. Fuel Process. Technol. 2007, 88, 833-845. [CrossRef]

35. Prabha, K.; Dasila, I.R.; Choudhury, D.N.; Saraf, V.; Kagdiyal, S.; Rajagopal, S.J.; Chopra, S.J. Estimation of FCC feed composition from routinely measured lab properties through ANN model. Fuel Process. Technol. 2014, 125, 155-162.

36. Sheppard, C.M.; Green, J.B.; Vanderveen, J.W. Relating feedstock composition to product slate and composition in catalytic cracking. 4. An extended pendant-core model for gasoline composition. Energy Fuels 1998, 12, 320-328. [CrossRef]

37. Li, Z.-K.; Wang, G.; Shi, Q.; Xu, C.-M.; Gao, J.-S. Retardation effect of basic nitrogen compounds on hydrocarbons catalytic cracking in coker gas oil and their structural identification. Ind. Eng. Chem. Res. 2011, 50, 4123-4132. [CrossRef]

38. Mondal, S.; Yadav, A.; Kumar, R.; Bansal, V.; Das, S.K.; Christopher, J.; Kapur, G.S. Molecular-level structural insight into clarified oil by nuclear magnetic resonance (NMR) spectroscopy: Estimation of hydrocarbon types and average structural parameters. Energy Fuels 2017, 31, 7682-7692. [CrossRef]

39. Li, W.; Chen, Y.; Zhang, L.; Xu, Z.; Sun, X.; Zhao, S.; Xu, C. Supercritical fluid extraction of FCC slurry oil: Bulk property and molecular composition of narrow fraction. Energy Fuels 2016, 30, 10064-10071. [CrossRef]

40. Nesumi, Y.; Oyama, T.; Todo, Y.; Azuma, A.; Mochida, I.; Korai, Y. Properties of fluid catalytic cracking decant oils of different origins in their single carbonization and cocarbonization with a petroleum vacuum residue. Ind. Eng. Chem. Res. 1990, 29, 1793-1801. [CrossRef]

41. VanNes, K.; VanWesten, H.A. Aspects of the Constitution of Mineral Oils; Elsevier: New York, NY, USA, 1951.

42. Riazi, M.R. Prediction of Thermophysical Properties of Petroleum Fractions. Ph.D. Thesis, The Pennsylvania State University, University Park, PA, USA, 1979.

43. Altgeld, K.H.; Boduszynski, M. Composition and Analysis of Heavy Petroleum Fractions; Marcel Dekker, Inc.: New York, NY, USA, 1994.

44. Stratiev, D.; Nenov, S.; Shishkova, I.; Georgiev, B.; Argirov, G.; Dinkov, R.; Yordanov, D.; Atanassova, V.; Vassilev, P.; Atanassov, K. Commercial investigation of the ebullated-bed vacuum residue hydrocracking in the conversion range of 55-93\%. ACS Omega 2020, 5, 33290-33304. [CrossRef]

45. Todorova-Yankova, L.; Yordanov, D.; Stratiev, D.; Shishkova, I. Investigation on SARA composition of light, medium, heavy, and extra heavy crude oils, and oil sands, and bitumen. Ind. Technol. 2021. article in press. (In Bulgarian)

46. Stratiev, D.S.; Shishkova, I.K.; Dinkov, R.K.; Petrov, I.P.; Kolev, I.V.; Yordanov, D.; Sotirov, S.; Sotirova, E.; Atanassova, V.; Ribagin, S.; et al. Crude slate, FCC slurry oil, recycle, and operating conditions effects on H-Oil product quality. Processes 2021, 9, 952. [CrossRef] 
47. Jacob, S.M.; Gross, B.; Voltz, S.E.; Weekman, V.W. A lumping and reaction scheme for catalytic cracking. AIChE J. 1976, 22, 701-713. [CrossRef]

48. Ancheyta-Juarez, J.; Lopez-Isunza, F.; Aguilar-Rodriguez, E.; Moreno-Mayorga, J.C. A strategy for kinetic parameter estimation in the fluid catalytic cracking process. Ind. Eng. Chem. Res. 1997, 36, 5170-5174. [CrossRef]

49. Higher Alkanes. Available online: https://en.wikipedia.org/wiki/Higher_alkanes (accessed on 10 June 2021).

50. Mitkova, M.; Stratiev, D.; Shishkova, I.; Dobrev, D. Thermal and Thermo-Catalytic Processes for Heavy Oil Conversion; Professor Marin Drinov Publishing House of Bulgarian Academy of Sciences: Sofia, Bulgaria, 2017.

51. Das, S.; Suganthan, P.N. Differential evolution: A survey of the state-of-the-art. IEEE Trans. Evol. Comput. 2011, 15, 4-31. [CrossRef]

52. ASTM International. ASTM International. ASTM D 2007-19. In Standard Test Method for Characteristic Groups in Rubber Extender and Processing Oils and Other Petroleum-Derived Oils by the Clay-Gel Absorption Chromatographic Method; ASTM International: West Conshohocken, PA, USA, 2019.

53. Stratiev, D.; Shishkova, I.; Ivanov, M.; Dinkov, R.; Georgiev, B.; Argirov, G.; Atanassova, V.; Vassilev, P.; Atanassov, K.; Yordanov, D.; et al. Role of catalyst in optimizing fluid catalytic cracking performance during cracking of h-oil-derived gas oils. ACS Omega 2021, 6, 7626-7637. [CrossRef] [PubMed]

54. Stratiev, D.; Shishkova, I.; Nikolova, R.; Tsaneva, T.; Mitkova, M.; Yordanov, D. Investigation on precision of determination of SARA analysis of vacuum residual oils from different origin. Pet Coal 2016, 58, 109-119.

55. Stratiev, D.; Shishkova, I.; Tsaneva, T.; Mitkova, M.; Yordanov, D. Investigation of relations between properties of vacuum residual oils from different origin, and of their deasphalted and asphaltene fractions. Fuel 2016, 170, 115-129. [CrossRef]

56. Liñan, L.Z.; Lima, N.M.N.; Maciel, M.R.W.; Filho, R.M.; Medina, L.C.; Embiruçu, M. Correlation for predicting the molecular weight of Brazilian petroleum residues and cuts: An application for the simulation of a molecular distillation process. J. Pet. Sci. Eng. 2011, 78, 78-85. [CrossRef]

57. Sánchez-Lemus, M.; Schoeggl, F.; Taylor, S.; Yarranton, H. Physical properties of heavy oil distillation cuts. Fuel 2016, 180, 457-472. [CrossRef] 